\title{
Economia Solidária como Política Pública: um olhar para ampliação e consolidação da agricultura familiar
}

\author{
Exzolvildres Queiroz Neto ${ }^{1}$ \\ José Victor Franklin Gonçalves de Medeiros ${ }^{2}$
}

\begin{abstract}
Resumo
Considerando que a agricultura familiar é um ponto estratégico para o desenvolvimento do Brasil - e assim ocupando papel de elevada importância para a Economia Solidária, mas que também o cooperativismo solidário exerce uma função indispensável para o fortalecimento da agricultura familiar, cabe analisar a Economia Solidária como política pública, investigando seu conteúdo. Para isso, inicialmente será realizada revisão bibliográfica acerca do conceito de cooperativismo e economia solidária, distinguindo-os. Num segundo momento abordar-se-á a lógica associativa e empreendedora das organizações solidárias, buscando-se compreender se são suficientes para sanar as dificuldades que se apresentam no meio rural. Por fim, será tratado da Economia Solidária como política pública e de que modo deve ser compreendido seu conteúdo para que haja expansão da agricultura familiar e do desenvolvimento rural.
\end{abstract}

Palavras-chave: Agricultura familiar. Economia Solidária. Política Pública.

\begin{abstract}
Considering that family farming is a strategic point for the development of Brazil - and thus occupying a role of great importance for the Solidarity Economy, but also that cooperative solidarity plays an indispensable role for the strengthening of family agriculture, it is possible to analyze the Solidary Economy as public policy, investigating its content. For this, initially will be carried out a bibliographical review about the concept of cooperativism and solidarity economy, distinguishing them. In a second moment the associative and enterprising logic of the solidarity organizations will be addressed, trying to understand if they are sufficient to remedy the difficulties that present themselves in the rural environment. Finally, Solidarity Economy will be treated as public policy and how its content should be understood so that there is expansion of family agriculture and rural development.
\end{abstract}

Keywords: Family farming. Solidarity Economy. Public Policy.

\section{Introdução}

Ao se observar os números que envolvem a agricultura familiar no Brasil, certamente pode-se considerá-la como um ponto estratégico para o desenvolvimento do

\footnotetext{
${ }^{1}$ Doutor em Engenharia Agrícola. Professor do Programa de Pós-Graduação em Políticas Públicas e Desenvolvimento (PPGPPD) da Universidade Federal da Integração Latino-Americana (UNILA). queiroz.neto@unila.edu.br

2 Mestrando do Programa de Pós-graduação em Políticas Públicas e Desenvolvimento (PPGPPD) da Universidade Federal da Integração Latino-Americana (UNILA). victorfmedeiros@gmail.com. Professor do Instituto Federal do Paraná.
} 
país, visto que este eixo, quando comparado à agricultura não familiar, é responsável por cerca de $40 \%$ da produção agrícola brasileira, representando $34,6 \%$ do valor bruto da produção, o equivalente a $\mathrm{R} \$ \mathbf{5 4 . 0 0 0 . 0 0 0 . 0 0 0}$ (cinquenta e quatro bilhões de reais), com 74,4\% do pessoal ocupado (12,3 milhões de pessoas), e responde por sete a cada dez empregos no campo do Brasil, tudo isso ocupando apenas 24,3\% da área total (ANUÁRIO..., 2015).

\section{Introdução}

Ao se observar os números que envolvem a agricultura familiar no Brasil, certamente pode-se considerá-la como um ponto estratégico para o desenvolvimento do país, visto que este eixo, quando comparado à agricultura não familiar, é responsável por cerca de $40 \%$ da produção agrícola brasileira, representando $34,6 \%$ do valor bruto da produção, o equivalente a $\mathrm{R} \$ \mathbf{5 4 . 0 0 0 . 0 0 0 . 0 0 0}$ (cinquenta e quatro bilhões de reais), com $74,4 \%$ do pessoal ocupado (12,3 milhões de pessoas), e responde por sete a cada dez empregos no campo do Brasil, tudo isso ocupando apenas 24,3\% da área total (ANUÁRIO..., 2015).

Outro dado que se destaca é o total de estabelecimento de agricultura familiar comparado à não familiar, representando $84,4 \%$ do total, isto é, 4.367 .902 (quatro milhões trezentos e sessenta e sete mil novecentos e dois) estabelecimentos (ANUÁRIO..., 2015). Dentro desse quantitativo, é fundamental mencionarmos a relevância do cooperativismo à agricultura familiar, na eficácia em mitigar os riscos e necessidade de condições especiais que suas atividades, mesmo diante de tamanhos avanços, ainda se encontram sujeitas, além do maior poder de negociação quando da aquisição de insumos e distribuição aos cooperados, obtendo, por meio das cooperativas, redução significativa dos custos de uma transação comercial, não por acaso $72 \%$ das propriedades agrícolas registradas na Organização das Cooperativas Brasileiras (OCB) são de agricultores familiares (ANUÁRIO..., 2015).

Quanto à vertente específica da economia solidária, o meio rural é onde atuam a maioria de suas iniciativas econômicas. É o que apontam os dados extraídos de mapeamento realizado pela Incubadora de Economia Solidária e Desenvolvimento Sustentável da Unijuí, em que, dentre os 264 empreendimentos de economia solidária participantes de tal levantamento, $47,7 \%$ afirmaram que sua área de atuação é apenas rural, e outros $26,9 \%$ que exercem atividades rurais e urbanas (LEMES, 2008), dados que se confirmam em números 
ainda mais expressivos no Segundo Mapeamento Nacional de Empreendimentos Econômicos Solidários realizados pela Secretaria Nacional de Economia Solidária, finalizado em 2013.

A relevância do cooperativismo fica evidenciada quando a Organização das Nações Unidas (ONU) declarou o ano de 2012 como sendo o ano internacional das cooperativas, destacando a importância destas sociedades de pessoas para a geração de empregos, redução da pobreza e integração social, incentivando os indivíduos, comunidades e governos a promover a formação e crescimento das cooperativas.

Tabela 1 - Área de atuação do empreendimento de Economia Solidária - 2013

\begin{tabular}{lcccc}
\hline Local & Rural & Urbana & Rural e urbana & No EES \\
\hline Centro-oeste & 1.082 & 670 & 269 & 2.021 \\
Nordeste & 5.804 & 1.554 & 682 & 8.040 \\
Norte & 1.566 & 1.270 & 290 & 3.127 \\
Sudeste & 959 & 1.970 & 299 & 3.228 \\
Sul & 1.382 & 1.392 & 518 & 3.292 \\
\hline Total & 10.793 & 6.856 & 2.058 & 19.708 \\
\hline
\end{tabular}

Fonte: Atlas Digital - Projeto SIES, dados do Segundo Mapeamento Nacional de Empreendimentos Econômicos Solidários de 2013 (SENAES).

Em 2014 foi eleito o ano internacional da Agricultura Familiar, reconhecendo que a importância deste setor para a produção de alimentos inclusiva e sua contribuição à segurança alimentar. Ainda, a Organização das Nações Unidas para a Alimentação e a Agricultura (FAO, sigla proveniente do termo na língua inglesa Food and Agriculture Organization of the United Nations) apontou para a agricultura familiar do Brasil papel de destaque na produção de alimentos para suprir a demanda que será gerada até no ano de 2050, quando há a probabilidade de a população mundial chegar aos 9 bilhões de habitantes.

Cabe, então, analisar a Economia Solidária como política pública, dado sua relevância para a ampliação da agricultura familiar, sua inserção e manutenção no mercado. Para isso, inicialmente se verá o conceito de cooperativismo e economia solidária, distinguindo-os. Num segundo, momento abordar-se-á a lógica associativa e empreendedora das organizações solidárias, buscando-se compreender se são suficientes para sanar as 
dificuldades que se apresentam no meio rural. Por fim, será tratado da Economia Solidária como política pública e da consequência de seu conteúdo para a expansão da agricultura familiar e do desenvolvimento rural.

\section{Dos conceitos de Cooperativismo e Economia Solidária}

Apesar da estreita relação existente, não significa, entretanto, que o Cooperativismo e Economia Solidária sejam sinônimos. Tamanha é a dificuldade em distinguir e dissociar tais conceitos, que em levantamento realizado por órgão oficial brasileiro - Secretaria Nacional da Economia Solidária (SENAES), o critério diferencial utilizado para identificar qual estrutura estaria vinculada à Economia Solidária foi a autogestão, o que, somado aos demais fatores elencados abaixo, não pode ser capaz de excluir dos dados levantados, por exemplo, uma cooperativa empresarial, conforme será exposto adiante nesse tópico:

Para o SIES Empreendimento Econômico Solidário (EES) são organizações que possuem as seguintes características:

- coletivas - serão consideradas as organizações suprafamiliares, singulares e complexas, tais como: associações, cooperativas, empresas autogestionárias, grupos de produção, clubes de trocas, redes etc.;

- cujos participantes ou sócios(as) são trabalhadores(as) dos meios urbano e rural que exercem coletivamente a gestão das atividades, assim como a alocação dos resultados;

- permanentes, incluindo os empreendimentos que estão em funcionamento e aqueles que estão em processo de implantação, com o grupo de participantes constituído e as atividades econômicas definidas;

- que disponham ou não de registro legal, prevalecendo a existência real e

- que realizam atividades econômicas de produção de bens, de prestação de serviços, de fundos de crédito (cooperativas de crédito e os fundos rotativos populares), de comercialização (compra, venda e troca de insumos, produtos e serviços) e de consumo solidário (SENAES, 2013, p. 1).

Quanto à espécie legal societária, as cooperativas, independentemente se empresariais ou de economia solidária, são consideradas sociedade de pessoas, destinadas a atividades econômicas, existindo propriedade conjunta e gestão democrática. Sintetizando suas características, é através da noção de cooperativa consagrada pela Aliança Cooperativa Internacional e trazida por Namorado (2009) em sua obra que se verifica o verdadeiro objetivo da cooperativa: 
Uma cooperativa é uma associação autônoma de pessoas unidas voluntariamente para prosseguirem as suas necessidades e aspirações comuns, quer econômicas, quer culturais, através de uma empresa comum democraticamente controlada (NAMORADO, 2009, p. 96).

O cooperativismo pode estar vinculado à economia solidária, o qual coloca o homem como finalidade da atividade econômica, distinguindo-se do cooperativismo chamado tradicional. Essa vertente, também denominada de cooperativismo empresarial, busca manter a estrutura vigente no sistema empresarial capitalista, utilizando predominantemente a força de trabalho assalariada e também a heterogestão. Imprime como uma das metas fundamentais o crescimento das sobras. Esta classificação das cooperativas fica mais evidente na explanação de Pinho (2004):

As primeiras, também denominadas tradicionais, estão voltadas para a competição do mercado e funcionam como empresas empenhadas na profissionalização da gestão, administração racional, aumento do capital, crescimento econômico e em moderna tecnologia para obter ganhos de escala e de eficiência, principalmente via fusão e incorporação (PINHO, 2004, p. 133).

$[\ldots]$

A Economia Solidária destaca a pessoa humana como o sujeito e o fim da atividade econômica, procurando recuperar a dimensão ética e humana das atividades econômicas e opondo-se a um modelo econômico único para todas as culturas e todas as sociedades. Tenta, então, desenvolver princípios mínimos adaptáveis a cada realidade (PINHO, 2004, p. 174).

No que tange à Economia Solidária, Laville e Gaiger (2009, p. 162) afirmam que o termo foi cunhado na década de 1990 e admitem a existência de variadas acepções, destacando que em todos os locais onde é estudada e praticada, seu conceito é organizado "ao redor da ideia de solidariedade, em contraste com o individualismo utilitarista que caracteriza o comportamento econômico predominante nas sociedades de mercado". Igualmente, Singer (2003) aponta a solidariedade como fator que o distingue das demais sociedades de produção econômica, individualizando a economia solidária ao afirmar que seu conceito

[...] se refere a organizações de produtores, consumidores, poupadores, etc., que se distinguem por duas especificidades: (a) estimulam a solidariedade entre seus membros mediante a prática da autogestão e (b) praticam a solidariedade para com a população trabalhadora em geral, com ênfase na ajuda aos mais desfavorecidos (SINGER, 2003, p. 116). 
De acordo com Lisboa (2004, p. 15), a economia solidária é um conjunto de pessoas, onde as atividades econômicas estão fundadas na ajuda recíproca de seus associados, onde todos contribuem para o bem-estar de cada um, tendo como características "a mínima presença de relações de assalariamento, e que dependem da contínua realização do seu próprio fundo de trabalho para sua reprodução". Complementando, em destaque às pessoas que se uniram em busca de uma vida melhor frente às dificuldades econômicas e sociais decorrentes da exclusão proporcionada pelo capitalismo, conceitua-se a economia solidária nos seguintes termos:

[...] conjunto de atividades econômicas e práticas sociais desenvolvidas pelos setores populares no sentido de garantir, com a utilização de sua própria força de trabalho e dos recursos disponíveis, a satisfação de necessidades básicas, tanto materiais como imateriais (ICAZA; TIRIBA, 2003, p. 101).

Diante dos conceitos transcritos é possível identificar as principais características da economia solidária. Primeiramente, a gestão diferencia-se das outras organizações econômicas porque deve ser associativa democrática, ou seja, cada associado equivale a um voto, indiferentemente de quota-parte, atribuindo a cada um empoderamento isonômico. Muito embora as características acima elencadas sejam importantes, é imprescindível que os associados da economia solidária sejam capazes de cessar com a visão individualista e busquem o bem-estar coletivo, por meio da cooperação. Ao romper com essa lógica egoísta, destaca-se a solidariedade como um elemento imprescindível para sua concretização, o que a diferencia das demais organizações (LAVILLE; GAIGER, 2009; SINGER, 2003).

Há, portanto, uma linha extremamente tênue que diferencia os conceitos aqui trabalhados. Pode-se afirmar que os empreendimentos de Economia Solidária, via de regra, são instituídos legalmente como cooperativas, existindo forte relação entre os princípios daquela vertente e a história associativa desta. Todavia, podem as cooperativas estarem vinculadas à economia solidária, conforme exposto acima, adotando os critérios também mencionados, sintetizados em um valor não unicamente monetário, ou seja, em multirracionalidades econômicas, como também podem inserirem-se buscando exclusivamente aumento de capital, adotando práticas como, por exemplo, maior número de empregados assalariados comparado à quantidade de cooperados. 


\section{Da lógica associativa e empreendedora da Economia Solidária}

Sabe-se que as cooperativas, ao buscarem concretizar os valores de uma Economia Solidária, sustentam o caráter do vínculo associativo e da participação, essencialmente ligados à autogestão, um de seus princípios basilares, que consistem em um projeto de organização democrática em que a democracia direta é privilegiada, onde os cooperados debatem os pontos relevantes em assembleias, sem que para isso percebam remuneração ou necessitem de intermediários (MOTHÉ, 2009, p. 26).

Segundo Singer (2002), a autogestão tem o condão de ser eficiente, de modo que o empreendimento solidário seja capaz de se tornar economicamente produtivo, assim como torná-lo um centro de interação democrático e igualitário. Quanto a relação do associativismo e participação para a sobrevivência e consolidação das cooperativas, Gaiger (2001) sintetiza em duas proposições:

\footnotetext{
a) o êxito econômico dos empreendimentos mostra-se vinculado a condições cujo efeito positivo deriva proporcionalmente do seu caráter socialmente cooperativo, significando que a solidariedade no trabalho funciona como um vetor específico da competitividade e viabilidade das cooperativas; b) apesar da modesta margem de produção de excedentes, as cooperativas solidárias apresentam indicadores não desprezíveis de eficiência econômica e se inclinam a distribuir seus resultados equitativamente (GAIGER, 2001).
}

Entretanto, o próprio Gaiger (2013) adverte que o êxito de uma iniciativa solidária depende não apenas de uma lógica solidária, mas de articulá-la a uma lógica empreendedora, visando obter resultados através de ação planejada e da otimização dos fatores produtivos, humanos e materiais. Schumpeter (1982), ao analisar a figura do empresário, explana acerca do seu caráter empreendedor, afirmando ser o inovador combinando certos fatores de produção, tais como trabalho, terra, conhecimento, capital e capital social na produção de bens e serviços destinados a um mercado de certa forma competitivo, em um contexto específico.

Geralmente as pessoas tendem a imaginar que o empreendedorismo e o individualismo caminham em um mesmo sentido. No entanto, Gaiger (2013) aponta para a existência de uma relação contraditória. Na visão individualista, marca do sistema capitalista, as empresas procuram diversificar as formas de contrato, negociando individualmente, para assim escapar do confronto com o coletivo de trabalhadores, além de propor a separação do 
pensar-fazer, fragmentando o trabalho em atividades quase sempre repetitivas, gerando desestímulo e estratégias também individuais de sobrevivência no emprego. Isso faz com que a autonomia do trabalhador junto de seu caráter empreendedor seja retomado no processo produtivo, levando a estratégias coletivas por conquistas que sejam destinadas também para o grupo em que está inserido.

A união de pessoas em organizações coletivas certamente possui forte influência para a inserção e permanência dos agricultores familiares no mercado mediante uma lógica empreendedora, como se pode observar através do crescimento 386 para 3.408 empreendimentos fornecedores do Programa Nacional de Alimentação Escolar (PNAE) entre os anos de 2009 a 2014 (ANUÁRIO..., 2015).

Mais especificamente, o cooperativismo também contribui de modo relevante para o êxito de tais organizações sob o viés do empreendedorismo, isso em razão do seu poder de negociação e aquisição de insumos e fornecimento aos cooperados, reduzindo os custos de uma transação comercial. Ainda, a esse respeito dois outros tópicos merecem destaque. 0 pequeno agricultor, quando associado, obtém outros serviços como armazenamento, beneficiamento, industrialização e comercialização de sua produção, exemplificando tal afirmação através da capacidade estática de armazenamento brasileira, em que 20\% (30 milhões de toneladas) pertencem às cooperativas agropecuárias. O outro tópico a ser enfatizado é o papel das cooperativas quanto a difusão de tecnologias específicas para as necessidades do produtor rural, contando com mais de 6 mil técnicos de diferentes áreas prestando serviço aos cooperados (ANUÁRIO, 2015).

Todavia, de acordo com as informações recolhidas no Segundo Mapeamento Nacional de Empreendimentos Econômicos Solidários, realizados pela Secretaria Nacional de Economia Solidária, finalizado em 2013, podem ser feitas algumas considerações em relação à manutenção da união do grupo e à geração de renda adequada aos sócios. Estas questões envolvendo efetivação da participação e da autogestão continuam sendo os três principais desafios eleitos pelos responsáveis pelos empreendimentos analisados (Quadro 1). 


\section{Quadro 1 - Principais desafios do empreendimento de Economia Solidária - 2013}

\begin{tabular}{|c|c|c|c|c|c|c|c|c|c|c|}
\hline Local & $\begin{array}{l}\text { Viabilizar } \\
\text { economicamente } \\
0 \\
\text { empreendimento }\end{array}$ & $\begin{array}{l}\text { Gerar } \\
\text { renda } \\
\text { adequada } \\
\text { aos (às) } \\
\text { sócios } \\
\text { (as) }\end{array}$ & $\begin{array}{l}\text { Garantir } \\
\text { proteção } \\
\text { social } \\
\text { (previdência, } \\
\text { assistência } \\
\text { e saúde) } \\
\text { para os (as) } \\
\text { sócios (as) }\end{array}$ & $\begin{array}{l}\text { Efetivar a } \\
\text { participação } \\
\text { e a } \\
\text { autogestão }\end{array}$ & $\begin{array}{l}\text { Alcançar a } \\
\text { conscientização } \\
\text { e a politização } \\
\text { dos (as) sócios } \\
\text { (as) }\end{array}$ & $\begin{array}{l}\text { Alcançar maior } \\
\text { conscientização } \\
\text { ambiental dos } \\
\text { (as) sócios (as) }\end{array}$ & $\begin{array}{l}\text { Promover a } \\
\text { articulação com } \\
\text { outros } \\
\text { empreendimentos } \\
\text { e com o } \\
\text { movimento de } \\
\text { economia } \\
\text { solidária }\end{array}$ & $\begin{array}{l}\text { Manter a } \\
\text { união do } \\
\text { grupo/coletivo }\end{array}$ & Outro & $\begin{array}{l}\mathrm{N}^{0} \\
\text { EES }\end{array}$ \\
\hline Centro-oeste & 1.338 & 1.668 & 877 & 975 & 734 & 869 & 947 & 1.415 & 328 & 2.021 \\
\hline Nordeste & 5.383 & 5.672 & 3.216 & 3.132 & 2.793 & 2.746 & 3.270 & 3.837 & 1.233 & 8.040 \\
\hline Norte & 2.180 & 2.373 & 1.585 & 1.491 & 1.184 & 1.385 & 1.326 & 1.925 & 293 & 3.127 \\
\hline Sudeste & 2.214 & 2.404 & 1.247 & 1.685 & 1.085 & 1.124 & 1.557 & 1.892 & 519 & 3.228 \\
\hline Sul & 1.993 & 2.386 & 830 & 1.328 & 918 & 1.170 & 1.357 & 1.979 & 732 & 3.292 \\
\hline Total & 13.108 & 14.503 & 7.755 & 8.611 & 6.714 & 7.294 & 8.457 & 11.048 & 3.105 & 19.708 \\
\hline
\end{tabular}

Fonte: Atlas Digital - Projeto SIES, dados do Segundo Mapeamento Nacional de Empreendimentos Econômicos Solidários de 2013 (SENAES, 2013).

Isso mostra que o associativismo e o empreendedorismo, isoladamente, não são capazes de findar as dificuldades e desigualdades sociais encontradas no meio rural. Para tanto é necessário se pensar na Economia Solidária como política pública, como será visto adiante.

\section{Do conteúdo da Economia Solidária como Política Pública}

Em 28 de maio de 2003, fruto da proposição da sociedade civil, foi criada no âmbito do Ministério do Trabalho e Emprego (MTE), a Secretaria Nacional de Economia Solidária SENAES, que, segundo o próprio MTE, tem o objetivo viabilizar e coordenar atividades de apoio à Economia Solidária em todo o território nacional, visando à geração de trabalho e renda, à inclusão social e à promoção do desenvolvimento justo e solidário.

Certamente, para se chegar ao nível de criação de uma Secretaria Nacional da Economia Solidária, investindo recursos públicos para incentivo à criação e pesquisa acerca do tema, é necessário se pensar neste fenômeno como Política Pública. Esta, por sua vez, pode ser conceituada como “diretrizes, princípios norteadores de ação do poder público; regras e procedimentos para as relações entre poder público e sociedade, mediações entre 
atores da sociedade e do Estado", formuladas em leis ou programas que orientam ações (TEIXEIRA, 2002).

\begin{abstract}
Uma política pública é uma diretriz elaborada para enfrentar um problema público. [...]. Uma política pública possui dois elementos fundamentais: intencionalidade pública e resposta a um problema público; em outras palavras, a razão para o estabelecimento de uma política pública é o tratamento ou a resolução de um problema entendido como coletivamente relevante (SECCHI, 2013, p. 2).
\end{abstract}

Ocorre que, para fins de estudo de políticas públicas, é necessário compreender o papel que o governo exerce sobre o restante da sociedade, sendo que em um governo neoliberal retomam-se as teses clássicas do liberalismo, onde o Estado possui basicamente a função de garantir os direitos individuais, sem que isso interfira na sua esfera econômica. Para o neoliberalismo, as políticas públicas como ações estatais que regulamentam os desequilíbrios resultantes do processo de acumulação de capital, são tomados como impeditivo crescimento (HÖFLING, 2001).

Por outro lado, como mostra Heidemann e Salm (2010), as teorias neoliberais não prevaleceram no decorrer do século 20 , em razão de se desconsiderar a vida comunal do homem e os problemas trazidos pela liberdade de modo quase absoluto, fazendo com que o Estado procurasse promover o desenvolvimento da sociedade, surgindo as políticas que mais tarde seriam compreendidas por políticas públicas:

\footnotetext{
O chamado Estado mínimo garantia ao indivíduo plena liberdade de iniciativa em todos os campos de ação, pois o Estado não interferia ou interpunha entraves em seu caminho, na forma de leis e regulamentações ou políticas governamentais ou públicas. [...] Quanto maior era o espaço privado, menor era a ingerência do Estado sobre sua atuação e vice-versa.

Mas a liberdade quase absoluta dos indivíduos trouxe problemas, por desconsiderar as dimensões comunais da vida humana, com seus problemas e soluções pela via política. Por isso, no contrato social que prevaleceu no século 20 , a liberdade individual foi reduzida na proporção do poder exercido pela comunidade política para estabelecer leis e impor limites às atividades individuais, sobretudo no campo econômico. Cresceu então o papel do Estado e diminuiu a importância do mercado auto-regulado na regra do jogo da vida humana associada. (HEIDEMANN; SALM, 2010, p. 25).
}

Nesse sentido, o Estado distingue-se de governo, sendo que, para os fins do estudo em tela, aquele pode ser tomado como o conjunto de instituições permanentes que possibilitam a ação do governo, enquanto este seria o conjunto de programas e projetos específicos que uma parcela da sociedade propõe para todo o restante dela, "configurando- 
se a orientação política de um determinado governo que assume e desempenha as funções de Estado por um determinado período" (HÖFLING, 2001). Assim, política pública não é o mesmo que política governamental, nem tampouco se restringe a ela, destacando-se o papel que há na participação para que as políticas públicas não fiquem limitadas a este subgrupo.

Dada a importância da relação existente entre Estado e políticas públicas, já em 1964 Theodore Lowi classificou-as na provável mais conhecida tipologia, aprimorando o estudo posteriormente, com fundamento em uma máxima de que o conteúdo de uma política pública tem o poder de determinar o processo político, tornando-se fundamental seu estudo ao analista de determinada política, sendo o elemento mais básico de tal análise, a verificação de seu tipo. A tipologia segundo Lowi é sintetizada por Secchi (2013) do seguinte modo:

\footnotetext{
Políticas regulatórias: estabelecem padrões de comportamento, serviço ou produtos para atores públicos e privados. [...] a capacidade de aprovação ou não de uma política desse gênero é proporcional à relação de forças dos atores e interesses presentes na sociedade.

Políticas distributivas: geram benefícios concentrados para alguns grupos de atores e custos difusos para toda a coletividade/contribuintes. [...] A grande dificuldade no desempenho de políticas distributivas é a delimitação do grupo beneficiário (quem é e quem não é beneficiário). [...]

Políticas redistributivas: concedem benefícios concentrados a algumas categorias de atores e implicam custos concentrados sobre outras categorias de atores. É um tipo de política que provoca muitos conflitos, pois representa um jogo de soma zero. [...] no qual se formam duas elites, uma demandando que a política se efetive e a outra lutando para que a política seja descartada.

Políticas constitutivas: [...] são aquelas políticas que definem as competências, jurisdições, regras da disputa política e da elaboração de políticas públicas (SECCHI, 2013, p. 25-26).
}

Posteriormente, ainda que não se refira diretamente a Lowi em sua obra, a classificação de Teixeira (2002) adota a sua tipologia, distinguindo as políticas públicas, quanto à natureza ou grau da intervenção, em estruturais - que buscam interferir em relações estruturais, como o próprio nome diz, tais como renda e propriedade -, e em conjunturais ou emergenciais - que tem por objetivo suavizar uma situação imediata por um determinado tempo.

Nesse cenário, o conteúdo da Economia Solidária como política pública, onde está inserida entre as mencionadas classificações, certamente trará consequências e impactos 
sobre a agricultura familiar e, consequentemente, ao desenvolvimento rural, isso em decorrência de que cada tipo altera a dinâmica política de uma forma diferente.

\section{Considerações finais}

Entende-se que a agricultura familiar é um setor de extrema relevância para o desenvolvimento rural e a segurança alimentar. Ocupa papel de destaque também dentro da Economia Solidária, representando a principal área de atuação de seus empreendimentos. Por outro lado, é verdade que o cooperativismo solidário é de grande valor para o crescimento da agricultura familiar, sua inserção no mercado, crescimento e manutenção.

Apesar da estreita relação existente, não significa que o Cooperativismo e Economia Solidária sejam sinônimos. Os empreendimentos solidários, via de regra, são instituídos legalmente como cooperativas, existindo ligação estreita entre os princípios daquela vertente e a história associativa desta. Todavia, podem as cooperativas estarem vinculadas à economia solidária, adotando critérios sintetizados em um valor não unicamente monetário, como também podem inserirem-se buscando exclusivamente aumento de capital, as chamadas cooperativas empresariais.

As cooperativas, ao buscarem concretizar os valores de uma Economia Solidária, sustentam o caráter do vínculo associativo e da participação, essencialmente ligados à prática da autogestão democrática. Mas o êxito de uma iniciativa solidária não depende apenas de uma lógica solidária, mas também de uma articulação com uma lógica empreendedora, que não está vinculada, necessariamente, ao individualismo. No entanto, o associativismo e o empreendedorismo não são capazes, isoladamente, de findar com as dificuldades e desigualdades sociais encontradas no meio rural.

Assim, então, é necessário se pensar na Economia Solidária como uma política pública e, como tal, deve ser compreendida como uma política não apenas de governo e emergencial. Não deve ser entendida como uma orientação política somente por um determinado período de tempo para suavizar uma situação imediata, mas como política estrutural de Estado, com fim e potencial de ser capaz de interferir em relações basilares, como renda e trabalho. Assim, poderá ampliar o potencial da agricultura familiar, necessário para que se venha a suprir a expectativa de ser ela um fator indispensável para a alimentação dos prováveis nove bilhões de habitantes no mundo, em 2050. 


\section{Referências}

ANUÁRIO Brasileiro da Agricultura Familiar 2015. Erechim: Bota Amarela, 2015.

GAIGER, Luiz Inácio. Virtudes do trabalho nos empreendimentos econômicos solidários. Revista Latinoamericana de Estudios del Trabajo, VII, n. 13, p. 191-211. 2001.

GAIGER, Luiz Inácio. A economia solidária e a revitalização do paradigma cooperativo. Rev. bras. Ci. Soc., São Paulo, v. 28, n. 82, p. 211-228, 2013. Disponível em: $<$ http://www.scielo.br/scielo.php?script=sci_arttext\&pid=S010269092013000200013\&lng=en\&nrm=iso>. Acesso em: 16 jul. 2016.

ICAZA, Ana Mercedes Sarria; TIRIBA, Lia Vargas. Economia Popular. In: CATTANI, Antonio David (Org.). A outra economia. Porto Alegre: Veraz, 2003.

HEIDEMANN, Francisco G.; SALM, José Francisco (Orgs.) Políticas Públicas e desenvolvimento: bases epistemológicas e modelos de análise. Brasília: UNB, 2010.

HÖFLING, Eloísa de Mattos. Estado e políticas (públicas) sociais. Cadernos CEDES, v. 21, n. 55 , p. 30-41, 2001. Disponível em: <http://scielo.br/pdf/ccedes/v21n55/5539>. Acesso em: 4 jul. 2016.

LAVILLE, Jean-Louis; GAIGER, Luiz Inácio. Economia Solidária. In: CATTANI, Antonio David et al. (Orgs.) Dicionário Internacional da Outra Economia. Coimbra: Almedina, 2009.

LEMES, Fabio Roberto Moraes. A inserção da economia solidária no mercado: contradições e possibilidades. Otra Economía. vol. II. n. 2 - 10 sem./2008 - ISSN 1851-4715. Disponível em: <http://revistas.unisinos.br/index.php/otraeconomia/article/viewFile/1085/275>. Acesso em: 15 jul. 2016.

LISBOA, Armando de Melo. Socioeconomia solidária: marco conceitual latino-americano. IX Encontro Nacional de Economia Política. Uberândia: Sociedade Brasileira de Economia Política, 2004.

MOTHÉ, Daniel. Autogestão. In: CATTANI, Antonio David et al. (Orgs.). Dicionário internacional da outra economia. Coimbra: Almedina, 2009.

NAMORADO, Rui. Cooperativismo. In: CATTANI, Antonio David et al. (Orgs.). Dicionário Internacional da Outra Economia. Coimbra: Almedina, 2009.

PINHO, Diva Benevides. O Cooperativismo no Brasil: da vertente pioneira à vertente solidária. São Paulo: Saraiva, 2004.

SCHUMPETER, Joseph A. Teoria do Desenvolvimento Econômico. Uma investigação sobre lucros, capital, crédito, juro e o ciclo econômico. São Paulo: Abril Cultural, 1982. 
SECCHI, Leonardo. Políticas públicas: Conceitos, esquemas de análises, casos práticos. 2. ed. São Paulo: Cengage Learning, 2013.

SENAES. Secretaria Nacional de Economia Solidária. Sies - Divulgação dos dados preliminares. Boletim Informativo. ano V. Base de dados SIES, 2013.

SINGER, Paul. Introdução à Economia Solidária. São Paulo: Fundação Perseu Abramo, 2002. Economia solidária. In: CATTANI, Antonio David. (Org.). A outra economia. Porto Alegre: Veraz, 2003.

TEIXEIRA, Elenealdo Celso. O papel das Políticas Públicas no Desenvolvimento Local e na Transformação da Realidade. Salvador: AATR, 2002. 